\title{
Early adversity and 5-HTT/BDNF genes: new evidence of gene-environment interactions on depressive symptoms in a general population
}

\author{
M. Aguilera ${ }^{1}$, B. Arias ${ }^{1}$, M. Wichers ${ }^{2}$, N. Barrantes-Vidal ${ }^{3}$, J. Moya ${ }^{4}$, H. Villa ${ }^{4}$, J. van Os ${ }^{2}$, M. I. Ibáñez ${ }^{4}$, \\ M. A. Ruipérez ${ }^{4}$ G. Ortet ${ }^{4}$ and L. Fañanás ${ }^{1 *}$ \\ ${ }^{1}$ Unitat d'Antropologia, Departament Biologia Animal, Facultat de Biologia, Universitat de Barcelona and Institut de Biomedicina de la \\ Universitat de Barcelona (IBUB) and CIBER de Salud Mental (CIBERSAM), Instituto de Salud Carlos III, Spain \\ ${ }^{2}$ Department of Psychiatry and Neuropsychology, South Limburg Mental Health Research and Teaching Network, EURON, \\ Maastricht University, Maastricht, The Netherlands \\ ${ }^{3}$ Departament de Psicologia Clínica i de la Salut, Facultat de Psicologia, Universitat Autònoma de Barcelona and CIBER Salud Mental, \\ Instituto de Salud Carlos III, Barcelona, Spain \\ ${ }^{4}$ Departament de Psicologia Bàsica, Clínica i Psicobiologia, Facultat de Ciències Humanes i Socials, Universitat Jaume I, Spain
}

Background. Adverse childhood experiences have been described as one of the major environmental risk factors for depressive disorder. Similarly, the deleterious impact of early traumatic experiences on depression seems to be moderated by individual genetic variability. Serotonin transporter (5-HTT) and brain-derived neurotrophic factor (BDNF) modulate the effect of childhood adversity on adult depression, although inconsistencies across studies have been found. Moreover, the gene $\times$ environment $(\mathrm{G} \times \mathrm{E})$ interaction concerning the different types of childhood adversity remains poorly understood. The aim of this study was to analyse the putative interaction between the 5-HTT gene (5-HTTLPR polymorphism), the BDNF gene (Val66Met polymorphism) and childhood adversity in accounting for adult depressive symptoms.

Method. A sample of 534 healthy individuals filled in self-report questionnaires of depressive symptomatology [the Symptom Check List 90 Revised (SCL-90-R)] and different types of childhood adversities [the Childhood Trauma Questionnaire (CTQ)]. The 5-HTTLPR polymorphism (5-HTT gene) and the Val66Met polymorphism (BDNF gene) were genotyped in the whole sample.

Results. Total childhood adversity $(\beta=0.27, p<0.001)$, childhood sexual abuse (CSA; $\beta=0.17, p<0.001)$, childhood emotional abuse $(\beta=0.27, p<0.001)$ and childhood emotional neglect $(\beta=0.22, p<0.001)$ had an impact on adult depressive symptoms. CSA had a greater impact on depressive symptoms in Met allele carriers of the BDNF gene than in the Val/Val group $(F=5.87, p<0.0001)$, and in $S$ carriers of the 5-HTTLPR polymorphism (5-HTT gene) $(F=5.80, p<0.0001)$.

Conclusions. Childhood adversity per se predicted higher levels of adult depressive symptoms. In addition, BDNF Val66Met and 5-HTTLPR polymorphisms seemed to moderate the effect of CSA on adult depressive symptoms.

Received 23 July 2008; Revised 20 October 2008; Accepted 7 January 2009; First published online 12 February 2009

Key words: BDNF Val66Met, childhood adversity, depression, G $\times$ E interaction, 5-HTTLPR.

\section{Introduction}

Depression is a complex phenotype that involves affective, motivational, cognitive, physical and behavioural symptoms and also complex relationships between genetic and environmental factors (Levinson, 2006).

\footnotetext{
* Address for correspondence: Dr L. Fañanás, Unitat d'Antropologia, Departament Biologia Animal, Facultat Biologia, Universitat de Barcelona, Av. Diagonal 645, 08028 Barcelona, Spain. (Email: lfananas@ub.edu)
}

Adverse childhood experiences have been described as one of the major environmental risk factors for adult depression (Kendler et al. 1993, 2004; Kessler \& Magee, 1993). Converging evidence from neurobiology and epidemiology has suggested that early disrupting adverse events during development cause enduring brain dysfunction (Heim \& Nemeroff, 2002; Anda et al. 2006).

Corticolimbic circuits (the hippocampus, neocortex, amygdala, cerebellum and hypothalamus) have emerged as key zones in the modulation of affectivity and emotion. Serotonin (5-HT) has been found to play an important role in these corticolimbic circuits in 
which serotonin transporter (5-HTT) is involved in the main reuptake mechanism. In addition, abnormalities in 5-HT functionality have classically been implicated in the origin of affective disorders (Owens \& Nemeroff, 1998). Similarly, brain-derived neurotrophic factor (BDNF) has a key distribution in cerebral regions involved in emotional and behavioural regulation (Gratacos et al. 2007). Evidence suggests that it is crucial for normal adaptive responses to the effects of stress (Duman, 2002). It has been suggested that BDNF contributes to the genesis of depressive symptoms because (i) decreased plasma levels of BDNF are found in patients with major depression (Karege et al. 2002); (ii) up-regulation of BDNF in the hippocampus is produced after long-term antidepressant administration (Duman, 2002); and (iii) there is a down-regulation of BDNF in animal models of stress-induced depression (see review by Angelucci et al. 2005). There is also recent evidence suggesting that the BDNF and serotonin systems interact with each other to regulate the neural circuits involved in affective behaviours (see review by Martinowich \& Lu, 2008). That is, activation of 5-HT receptors can induce transcription of the BDNF gene and, conversely, BDNF can stimulate synaptic plasticity of 5-HT neuron axons (Mattson et al. 2004).

It is interesting to note that the maturation of these areas involved in higher-order functions, such as affective regulation, continues into childhood and adolescence (Lenroot \& Giedd, 2006). Thus, these brain areas might still be vulnerable to environmental insults during childhood and early adulthood.

The deleterious impact of early traumatic experiences on adult depressive symptoms and major depression is thought to be moderated by individual genetic variability, specifically in those genes regulating serotonin transmission such as the 5-HTT gene (Caspi et al. 2003; Kendler et al. 2005). In that respect, two studies have reported complex interactions between the 5-HTT gene and the BDNF gene on depression in individuals who had suffered childhood adversity (Kaufman et al. 2006; Wichers et al. 2008). However, neither of these two studies differentiated between types of childhood adversity and their conclusions are restricted to the type of sample used, namely children and female samples respectively.

Recent research highlights the importance of the nature of adverse childhood experiences regarding its interplay with these genetic variants for complex phenotypes such as suicide behaviour and anxiety sensitivity (Gibb et al. 2006; Roy et al. 2007; Perroud et al. 2008; Stein et al. 2008). However, none of these studies examined the putative interactions between the 5-HTT and BDNF genes and the effect of the nature of childhood adversity on adult depressive symptoms.
On the basis of this previous research, the aim of the present study was to detect the putative gene $\times$ gene $\times$ environment interaction $(\mathrm{G} \times \mathrm{G} \times \mathrm{E})$ between the 5-HTT gene (5-HTTLPR polymorphism), the BDNF gene (Val66Met polymorphism) and childhood adversity, in relation to the presence of depressive symptoms in adulthood, in a non-clinical adult sample.

\section{Method}

\section{Sample}

The sample consisted of 534 healthy Spanish individuals who were recruited from the campus of Jaume I University in Castelló (Spain) and from university offices and community technical schools from the metropolitan area of Barcelona (Spain). At the assessment $77 \%$ of the participants were students.

Exclusion criteria were the presence of any major medical illness affecting brain function, current substance abuse (alcohol or any illicit drug), neurological conditions, history of head injury and personal history of psychiatric medical treatment. These areas were screened by means of a short interview designed ad hoc for this study. In addition, participants were required to describe themselves as being of Spanish (Caucasian) ancestry to reduce the possibility of confounding by population stratification (Calafell \& Bertranpetit, 1994; Freedman et al. 2004). Trained psychologists carried out the screening for the exclusion criteria.

Ethical approval was obtained from local research ethics committees. All participants provided written informed consent before inclusion in the study.

\section{Measurements}

Participants filled in the 13-item depressive scale of the revised version of the Symptom Check List (SCL-90-R; Derogatis \& Melisaratos, 1983), a validated self-report questionnaire. This scale measures the degree of discomfort associated with each depressive symptom during the past week on a five-point scale ranging from 'not at all' to 'extremely'. A continuous weighted depressive symptoms score (sum of scores on the depression items divided by number of items filled in) was used in the analyses.

Childhood adversity was assessed by the shortened version of the Childhood Trauma Questionnaire (CTQ; Bernstein et al. 2003). The CTQ assessed five types of childhood adversity: emotional abuse, physical abuse, sexual abuse, emotional neglect and physical neglect. The reliability and validity of the CTQ have been demonstrated (Bernstein et al. 1994, 2003). The CTQ consists of 28 items (25 clinical and three validity items). The score for each item ranges from 
Table 1. Sociodemographic data and genotype/allele distribution for the 5-HTTLPR (5-HTT gene) and Val66Met (BDNF gene) polymorphisms

\begin{tabular}{|c|c|c|c|c|c|}
\hline \multicolumn{6}{|l|}{ Sociodemographic data } \\
\hline Gender distribution $(\mathrm{M} / \mathrm{F})$ & \multicolumn{5}{|l|}{$242 / 292$} \\
\hline Age in years, mean (s.D.), range & \multicolumn{5}{|c|}{$22.9(5.4), 18-50$} \\
\hline \multicolumn{6}{|l|}{ Completed education } \\
\hline Elementary school (\%) & \multicolumn{5}{|l|}{3.3} \\
\hline High school (\%) & \multicolumn{5}{|l|}{85.7} \\
\hline University education (\%) & \multicolumn{5}{|l|}{10.9} \\
\hline Genotype and allele distribution, $n(\%)$ & \multicolumn{3}{|c|}{ Genotype distribution } & \multicolumn{2}{|c|}{ Allele distribution } \\
\hline \multicolumn{6}{|l|}{ 5-HTT gene } \\
\hline \multirow[t]{2}{*}{ 5-HTTLPR polymorphism $(n=475)$} & $\mathrm{L} / \mathrm{L}$ & $\mathrm{L} / \mathrm{S}$ & $\mathrm{S} / \mathrm{S}$ & Allele L & Allele S \\
\hline & $119(25.1)$ & $230(48.4)$ & $126(26.5)$ & $468(49.3)$ & $482(50.7)$ \\
\hline \multicolumn{6}{|l|}{ BDNF gene } \\
\hline \multirow[t]{2}{*}{ Val66Met polymorphism $(n=470)$} & Val/Val & Val/Met & Met/Met & Allele Val & Allele Met \\
\hline & $282(60)$ & $159(33.8)$ & $29(6.2)$ & $723(76.9)$ & $217(23.1)$ \\
\hline
\end{tabular}

M, Male; F, female; s.D., standard deviation.

Frequencies were found in Hardy-Weinberg equilibrium (5-HTTLPR polymorphism $\chi^{2}=0.21, \mathrm{df}=2, p=0.90$; Val66Met polymorphism $\left.\chi^{2}=0.52, \mathrm{df}=2, p=0.77\right)$.

1 to 5 according to the extent to which subjects agree with the statement. A composite index of total childhood adversity was calculated as the mean score of the five dimensions.

\section{Laboratory methods}

Genomic DNA was extracted from saliva samples using the Collection Kit BuccalAmp DNA extraction kit (Epicentre, Barcelona, Spain). The 48-bp insertion/ deletion at the 5' promoter region of the 5-HTT gene (5HTTLPR polymorphism) was analysed using the protocol described previously (Lesch et al. 1996; Heils et al. 1997). The SNP rs6265 (Val66Met) of the BDNF gene was genotyped using Applied Biosystems (AB, Madrid, Spain) TaqMan technology. The AB assay-ondemand service was used to order the probes. Randomized individuals were re-genotyped to confirm the pattern reproducibility.

\section{Statistical analyses}

The main effects of each type of adversity and composite index of total childhood adversity on depressive symptoms and of the 5-HTTLPR or Val66Met genotype on depressive symptoms were analysed. In addition, the main effects of the 5-HTTLPR or Val66Met genotype on each type of adversity and total childhood adversity were explored.

Two-way interaction effects between (i) 5-HTTLPR and Val66Met polymorphisms, (ii) 5-HTTLPR and each type of adversity/total childhood adversity and (iii) the Val66Met polymorphism and each type of adversity/total childhood adversity were fitted in models of depressive symptomatology. When the $\mathrm{G} \times \mathrm{E}$ interaction was significant, post-hoc analyses were performed by means of the Stata lincom command to evaluate the dose-response relationship (UCLA: Academic Technology Services, 2008). Differences in slopes between genotypes were tested at the mean (none or minimal severity levels of maltreatment), at one standard deviation (1 s.D.) above the mean (low to moderate severity levels of maltreatment) and at 2 S.D. above the mean (moderate to severe severity levels of maltreatment). Finally, a three-way interaction was performed between the measured polymorphisms and total childhood adversity on depressive symptoms.

All analyses were carried out using linear regression. Effects sizes were calculated and evaluated by the Wald test using the Stata lincom command. All regression analyses were controlled for age and sex. Values for the standardized coefficient $(\beta)$ are displayed in the results section. Analyses were performed using Stata 9.1 (StataCorp, 2005). Power simulation analysis confirmed that, with an $\alpha$ level of 0.05 , in our sample we had sufficient power $(>0.90)$ to detect effect sizes of 0.2 .

As the BDNF 'Met/Met' group was small $(n=29)$, 'Met' carriers ('Met/Met' +' Val/Met') were grouped in subsequent analyses.

\section{Results}

Sociodemographic data and allele/genotype distribution are shown in Table 1 . The average score on 
Table 2. Mean scores for types of childhood adversity and total childhood adversity

\begin{tabular}{lllc}
\hline $\begin{array}{l}\text { Type of adversity } \\
(n=521)\end{array}$ & Mean (S.D.) & $\beta$ & $p$ value \\
\hline Emotional abuse & $6.6(2.6)$ & 0.27 & $<0.0001$ \\
Physical abuse & $5.4(0.9)$ & 0.08 & 0.06 \\
Sexual abuse & $5.5(2.0)$ & 0.17 & $<0.0001$ \\
Emotional neglect & $8.3(3.1)$ & 0.22 & $<0.0001$ \\
Physical neglect & $5.7(1.4)$ & 0.07 & 0.10 \\
Total adversity & $6.1(1.4)$ & 0.27 & $<0.0001$ \\
\hline
\end{tabular}

S.D., Standard deviation.

All regressions were adjusted for age and sex.

$\beta$ (standardized coefficient) was derived from the main effects of total/types of childhood adversities on adult depressive symptoms.

depressive symptoms was 0.7 (S.D. $=0.6$, range $0-3.2$ ). A main effect of total childhood adversity on adult depressive symptoms was detected $(\beta=0.27, p<$ $0.001)$. Specifically, childhood sexual abuse (CSA; $\beta=$ $0.17, p<0.001)$, childhood emotional abuse $(\beta=0.27$, $p<0.001)$ and childhood emotional neglect $(\beta=0.22$, $p<0.001)$ are related significantly to depressive symptomatology in adulthood.

No other associations between other types of childhood adversity and depressive symptoms were found (Table 2). No significant associations were found between either 5-HTTLPR or Val66Met genotypes on depressive symptoms. However, an association of the 5-HTTLPR genotype on CSA was found (L/S: $\beta=-0.33, p=0.006$; S/S: $\beta=-0.18, p=0.17$; using L/ $\mathrm{L}$ as the reference category). The $\mathrm{L} / \mathrm{L}$ genotype presented a higher level of CSA compared to the L/S genotype, but compared to the $\mathrm{S} / \mathrm{S}$ genotype the difference did not reach a significant level.

Concerning two-way interactions, a significant $\mathrm{G} \times \mathrm{E}$ interaction was found for 5-HTTLPR genotypes and CSA in the model of depressive symptoms $(F=4.36, p<0.0001)$. In subjects with $\mathrm{L} / \mathrm{S}$ and $\mathrm{S} / \mathrm{S}$ genotypes, the effect of CSA on adult depressive symptoms was higher than in $\mathrm{L} / \mathrm{L}$ subjects $(\mathrm{L} / \mathrm{S} \times$ sexual abuse: $\beta=0.25, p=0.03$; $\mathrm{S} / \mathrm{S} \times$ sexual abuse: $\beta=0.18$, $p=0.07 ; \mathrm{L} / \mathrm{L}$ reference category). When we compared $\mathrm{S}$ allele carriers $(\mathrm{S} / \mathrm{L}+\mathrm{S} / \mathrm{S})$ to $\mathrm{L} / \mathrm{L}$ individuals, we detected a higher effect of CSA on depressive symptoms $(\beta=0.21, p=0.016)$ (Fig. 1). Post-hoc analysis showed a dose-response relationship between 5HTTLPR genotypes and CSA for depressive symptoms. That is, the interaction was only significant when the CSA score was above average: the difference in slope between $\mathrm{S}$ allele carriers and $\mathrm{L} / \mathrm{L}$ regression lines reached a significant level at 1 s.D. above the mean (low

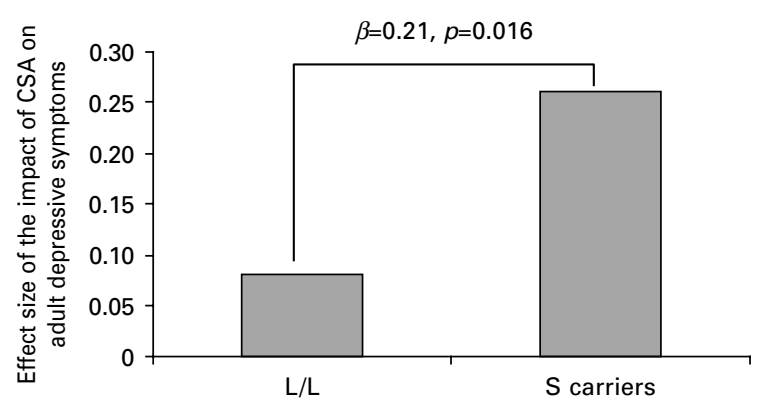

Fig. 1. Effect size of childhood sexual abuse (CSA) on adult depressive symptoms by the 5-HTTLPR genotype: the effect of CSA has a higher impact on adult depressive symptoms in $S$ carriers than in the L/L group $(n=452) . F=5.80, p<0.0001$ (adjusted for age and sex); $\beta=$ standardized coefficient.

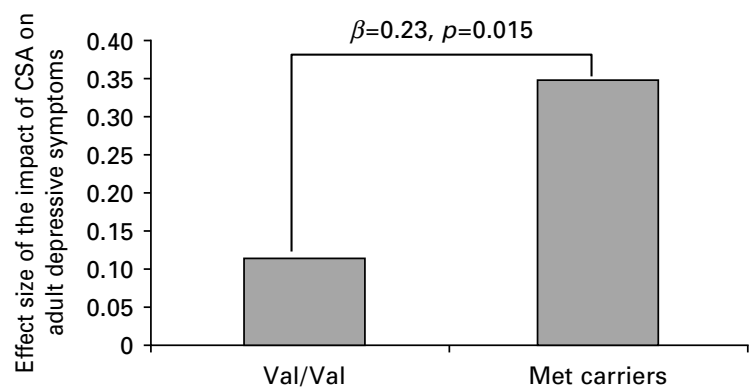

Fig. 2. The depressogenic effect of childhood sexual abuse (CSA) is moderated by the brain-derived neurotrophic factor (BDNF) genotype: the effect of CSA has a higher impact on adult depressive symptoms in Met carriers than in the Val/ Val group $(n=456) . F=5.87, p<0.0001$ (adjusted for age and sex); $\beta=$ standardized coefficient.

to moderate severity levels $)(\beta=0.28, t=2.07, p=0.039)$ and this difference increased at 2 S.D. above the mean (moderate to severe severity levels) $(\beta=0.49, t=2.45$, $p=0.015$ ).

In addition, a two-way interaction with the Val66Met genotype was found $(F=5.87, p<0.0001$; $\beta=0.23, p=0.015, \mathrm{Val} / \mathrm{Val}$ reference category). CSA had a greater effect on adult depressive symptoms in Met carriers than in Val/Val individuals (Fig. 2). Posthoc analysis also revealed a dose-response relationship, the differences in slope between Met allele carriers and $\mathrm{Val} / \mathrm{Val}$ was statistically significant only at 1 S.D. above the mean (low to moderate severity levels) $(\beta=0.32, t=2.42, p=0.016)$, and it increased at 2 s.D. above the mean (moderate to severe severity levels) $(\beta=0.55, t=2.62, p=0.009)$. No significant $\mathrm{G} \times \mathrm{E}$ interactions were found for the other subdimensions of childhood adversity or on adult depressive symptoms.

We did not detect a three-way interaction between the 5-HTT gene, the BDNF gene and total childhood adversity on adult depressive symptoms. 


\section{Discussion}

Our results show that experiences of CSA, emotional abuse and emotional neglect predicted per se the presence of adult depressive symptoms, in accordance with previous clinical and epidemiological reports (Chapman et al. 2004; Anda et al. 2006).

From the perspective of $\mathrm{G} \times \mathrm{E}$ interaction, our results suggest that genetic variability at the 5-HTT and BNDF genes moderates the effect of childhood adversity on adult depressive symptoms. Specifically, our findings show that CSA impacts more strongly on adult depressive symptomatology in $S$ carriers of the 5-HTTLPR polymorphism (5-HTT gene) than in the LL group, and in Met allele carriers of the Val66Met polymorphism (BDNF gene) compared to the Val/Val group. Moreover, a dose-response relationship was found in both models of $\mathrm{G} \times \mathrm{E}$ on adult depressive symptoms.

These results are consistent with those found in adult psychiatric patients with suicidal behaviour. For example, Gibb et al. (2006) found that the 5-HTTLPR polymorphism moderates the effect of childhood sexual and physical, but not emotional, abuse on suicide attempters. The 5-HTT gene has also been linked to $\mathrm{G} \times \mathrm{E}$ interaction for other types of adversity such as emotional neglect (Roy et al. 2007). Additionally, Perroud et al. (2008), based on a large sample of suicide attempters genotyped for the BNDF gene, detected a $\mathrm{G} \times \mathrm{E}$ interaction for severity of suicidal attempt in individuals who had experienced CSA.

CSA may differ from other types of childhood adversity on its greater capacity to disrupt the underlying neurobiological structures involved in stress response. In this sense, it has been suggested that CSA increases sensitivity to the depressogenic adult life experiences (Kendler et al. 2004). In fact, neurobiological studies have shown (i) dysfunction of the hypothalamic-pituitary-adrenal (HPA) axis in women with a CSA history and (ii) volumetric reductions of the hippocampus and amygdala, the main regulatory mechanisms of the HPA axis, in women who had experienced CSA (Heim \& Nemeroff, 2001; Teicher et al. 2002; Nemeroff, 2004). It is also likely that this dysregulation of the HPA axis may be mediated by the genetic background of the individual such as 5-HTTLPR and Val66Met polymorphisms (Nestler et al. 2002; Brown \& Harris, 2008).

Of note, both polymorphisms of the analysed genes present functional consequences: the $S$ allele of the 5-HTTLPR polymorphism (5-HTT gene) has been related to reduced transcription of the serotonin transporter (Lesch et al. 1996) whereas the Met allele of the Val66Met polymorphism (BDNF gene) is reported to affect intracellular processing and secretion of the mature protein (Egan et al. 2003). From a $\mathrm{G} \times \mathrm{E}$ interaction point of view, the $S$ allele has been frequently involved in risk for depressive symptoms and major depression when childhood adversity and recent life events are considered (Caspi et al. 2003; Kendler et al. 2005; Uher \& McGuffin, 2008). Similarly, interaction between the Met allele of the BNDF polymorphism and childhood adversity was reported by Wichers et al. (2008).

However, in the above-mentioned study conducted by Perroud et al. (2008), the risk allele was the Val variant. This inconsistency between the proposed risk alleles of the BDNF Val66Met polymorphism has also been found by a meta-analysis within association genetic studies in several mental disorders (Gratacos et al. 2007). Further research is needed to better understand the pathophysiological consequences of this particular functional polymorphism in brain functioning.

Despite recent evidence that serotonin and BDNF systems may be linked at multiple intra- and intercellular levels (Martinowich \& Lu, 2008), our results did not find a direct interaction between the two polymorphisms explored. A study carried out by Kim et al. (2007) in an elderly population with categorical outcome of depression also found no interaction between these two genes. Further research may be needed to elucidate this complex relationship between the BDNF and 5-HT systems in the aetiology of depressive mood.

Unlike previous studies (Kaufman et al. 2006; Wichers et al. 2008) the three-way interaction between the 5-HTTLPR genotype, the Val66Met genotype, and childhood adversity on depressive symptoms was not detected in our sample. However, our study has certain differences that may account for this discrepancy. Our sample, composed of healthy men and women, was collected from the general population whereas Kaufman et al. (2006) focused their study on children with severe maltreatment histories, and Wichers et al. (2008) studied only a female sample. Negative results concerning the three-way interaction could also be due to the low frequency of individuals carrying both risk genotypes (SS Met carriers).

As in the study of Wichers et al. (2008), G $\times$ E correlation may play a role in addition to $\mathrm{G} \times \mathrm{E}$ interaction. A main effect of 5-HTTLPR polymorphism on CSA was found; that is, the L/L group showed higher levels of CSA compared to S allele carriers. Of note, despite the L/L group presenting higher levels of CSA, this group presented less severe adult depressive symptoms than the $\mathrm{S}$ allele carriers. However, as the $\mathrm{G} \times \mathrm{E}$ interaction analysis was not controlled for $\mathrm{G} \times \mathrm{E}$ correlation between these two variables, caution must be exercised in interpreting the two-way interaction effect (Pak, 2006). 
Although our results replicate previous published findings, there are some limitations that should be mentioned. The cross-sectional nature of our design did not allow causal associations to be tested robustly, although a priori hypotheses were clearly defined and guided all analyses. Although some studies have found high reliability of self-reports of childhood trauma (e.g. Fink et al. 1995), the retrospective measure of childhood adversity may be influenced by recall bias. It is important to emphasize that different prevalences between each type of childhood adversity in the population may affect the power to detect other $\mathrm{G} \times \mathrm{E}$ interactive effects. In the present sample, following the guidelines for classification of CTQ proposed by Bernstein \& Fink (1998), and in agreement with previous European surveys (Finkelhor, 1994; May-Chahal \& Cawson, 2005), the prevalence of (i) childhood emotional abuse is $15.5 \% \quad(n=83)$; (ii) childhood physical abuse is $4.1 \%(n=22)$; (iii) CSA is $9.2 \%(n=49)$; (iv) childhood emotional neglect is $27.2 \%(n=145)$; and physical neglect is $10.3 \%(n=55)$. Therefore, it seems that absence of interactions concerning other types of adversity, except for childhood physical abuse, may not be due to a simple function of low prevalence compared to the prevalence of CSA. Moreover, co-occurrence of CSA with other forms of childhood adversity has been described (Dong et al. 2003). To elucidate putative confounder effects of other childhood adversities on depressive symptoms, post-hoc analyses were carried out concerning significant results. Either the main effect of childhood adversity on adult depressive symptoms or $\mathrm{G} \times \mathrm{E}$ interactions on depressive symptoms remained significant after controlling for other childhood adversities (data available on request). However, other distal factors such as timing and duration in which CSA occurred, and other early environmental factors such as quality of parental care, may also play a role in determining individual vulnerability to depressive symptomatology during adulthood (Cotter, 1998; Hill et al. 2000; McCutcheon et al. 2008). Other current factors not controlled in the present study, such as medical status, work and social adjustment or quality of life, may influence the mood state of participants at the time of assessment. Finally, the triallelic nature of the 5-HTTLPR polymorphism (S, La and Lg) was not considered. It has been shown that $\mathrm{Lg}$ carriers present a similar expression to $\mathrm{S}$ carriers, although genotypes carrying $\mathrm{Lg}$ are not expected to have high frequencies in Caucasian populations $(\mathrm{SLg}=0.09, \mathrm{LgLg}=0.03)(\mathrm{Hu}$ et al. 2006).

Nevertheless, this study contributes to this field in certain unique ways. Depression has been described as a continuous phenotype in the population (Akiskal et al. 1997), so aetiopathogenic mechanisms should be detectable across a wide range of subclinical and clinical phenotypic variation in non-clinical samples such as the present one. In addition, this study has analysed the impact of both qualitatively distinct forms of childhood adversity and their level of global severity, which has been shown to be relevant when assessing the impact of trauma on health outcomes (Dong et al. 2004).

\section{Acknowledgments}

Mari Aguilera thanks the Departament d'Universitats, Recerca i Societat de la Informació (DURSI) de la Generalitat de Catalunya for a predoctoral grant (2004 FI 00673). This study was supported by the Ministerio de Educación y Ciencia (SAF 2005-07852-C02-01); the Ministerio de Sanidad y Consumo (05-317) and Fondos FEDER, Ministerio de Educación y Ciencia (Grant Number: SEJ2005-09307), Instituto de Salud Carlos III, CIBER de Salud Mental (CIBERSAM) and Institut de Biomedicina de la Universitat de Barcelona (IBUB).

\section{Declaration of Interest}

None.

\section{References}

Akiskal HS, Judd LL, Gillin JC, Lemmi H (1997). Subthreshold depressions: clinical and polysomnographic validation of dysthymic, residual and masked forms. Journal of Affective Disorders 45, 53-63.

Anda RF, Felitti VJ, Bremner JD, Walker JD, Whitfield C, Perry BD, Dube SHR, Giles WH (2006). The enduring effects of abuse and related adverse experiences in childhood: a convergence of evidence from neurobiology and epidemiology. European Archives of Psychiatry and Clinical Neuroscience 256, 174-186.

Angelucci F, Brene S, Mathe AA (2005). BDNF in schizophrenia, depression and corresponding animal models. Molecular Psychiatry 10, 345-352.

Bernstein DP, Fink L (1998). Childhood Trauma Questionnaire: A Retrospective Self-report. The Psychological Corporation: San Antonio.

Bernstein DP, Fink L, Handelsman L, Foote J, Lovejoy M, Wenzel K, Sapareto E, Ruggiero J (1994). Initial reliability and validity of a new retrospective measure of child abuse and neglect. American Journal of Psychiatry 151, 1132-1136.

Bernstein DP, Stein JA, Newcomb MD, Walker E, Pogge D, Ahluvalia T, Stokes J, Handelsman L, Medrano M, Desmond D, Zule W (2003). Development and validation of a brief screening version of the Childhood Trauma Questionnaire. Child Abuse and Neglect 27, 169-190.

Brown GW, Harris TO (2008). Depression and the serotonin transporter 5-HTTLPR polymorphism: a review and a hypothesis concerning gene-environment interaction. Journal of Affective Disorders 111, 1-12. 
Calafell F, Bertranpetit J (1994). Principal component analysis of gene frequencies and the origin of Basques. American Journal of Physical Anthropology 93, 201-215.

Caspi A, Sugden K, Moffitt TE, Taylor A, Craig IW, Harrington H, McClay J, Mill J, Martin J, Braithwaite A, Poulton R (2003). Influence of life stress on depression: moderation by a polymorphism in the 5-HTT gene. Science 301, 386-389.

Chapman DP, Whitfield CL, Felitti VJ, Dube SR, Edwards VJ, Anda RF (2004). Adverse childhood experiences and the risk of depressive disorders in adulthood. Journal of Affective Disorders 82, 217-225.

Cotter PA (1998). Sexual abuse is not the only childhood adversity that may lead to later depression. British Medical Journal 316, 1244.

Derogatis LR, Melisaratos N (1983). The Brief Symptom Inventory: an introductory report. Psychological Medicine 13, 595-605.

Dong M, Anda RF, Dube SR, Giles WH, Felitti VJ (2003). The relationship of exposure to childhood sexual abuse to other forms of abuse, neglect, and household dysfunction during childhood. Child Abuse and Neglect 27, 625-639.

Dong M, Anda RF, Felitti VJ, Dube SR, Williamson DF, Thompson TJ, Loo CM, Giles WH (2004). The interrelatedness of multiple forms of childhood abuse, neglect, and household dysfunction. Child Abuse and Neglect 28, 771-784.

Duman RS (2002). Synaptic plasticity and mood disorders. Molecular Psychiatry 7 (Suppl. 1), S29-S34.

Egan MF, Kojima M, Callicott JH, Goldberg TE, Kolachana BS, Bertolino A, Zaitsev E, Gold B, Goldman D, Dean M, Lu B, Weinberger DR (2003). The BDNF val66met polymorphism affects activity-dependent secretion of BDNF and human memory and hippocampal function. Cell 112, 257-269.

Fink LA, Bernstein D, Handelsman L, Foote J, Lovejoy M (1995). Initial reliability and validity of the childhood trauma interview : a new multidimensional measure of childhood interpersonal trauma. American Journal of Psychiatry 152, 1329-1335.

Finkelhor D (1994). The international epidemiology of child sexual abuse. Child Abuse and Neglect 18, 409-417.

Freedman ML, Reich D, Penney KL, McDonald GJ, Mignault AA, Patterson N, Gabriel SB, Topol EJ, Smoller JW, Pato CN, Pato MT, Petryshen TL, Kolonel LN, Lander ES, Sklar P, Henderson B, Hirschhorn JN, Altshuler D (2004). Assessing the impact of population stratification on genetic association studies. Nature Genetics 36, 388-393.

Gibb BE, McGeary JE, Beevers CG, Miller IW (2006). Serotonin transporter (5-HTTLPR) genotype, childhood abuse, and suicide attempts in adult psychiatric inpatients. Suicide and Life-Threatening Behavior 36, 687-693.

Gratacos M, Gonzalez JR, Mercader JM, De Cid R, Urretavizcaya M, Estivill X (2007). Brain-derived neurotrophic factor Val66Met and psychiatric disorders: meta-analysis of case-control studies confirm association to substance-related disorders, eating disorders, and schizophrenia. Biological Psychiatry 61, 911-922.
Heils A, Mossner R, Lesch KP (1997). The human serotonin transporter gene polymorphism: basic research and clinical implications. Journal of Neural Transmission 104, 1005-1014.

Heim C, Nemeroff CB (2001). The role of childhood trauma in the neurobiology of mood and anxiety disorders: preclinical and clinical studies. Biological Psychiatry 49, 1023-1039.

Heim C, Nemeroff CB (2002). Neurobiology of early life stress: clinical studies. Seminars in Clinical Neuropsychiatry 7, 147-159.

Hill J, Davis R, Byatt M, Burnside E, Rollinson L, Fear S (2000). Childhood sexual abuse and affective symptoms in women: a general population study. Psychological Medicine 30, 1283-1291.

Hu XZ, Lipsky RH, Zhu G, Akhtar LA, Taubman J, Greenberg BD, Xu K, Arnold PD, Richter MA, Kennedy JL, Murphy DL, Goldman D (2006). Serotonin transporter promoter gain-of-function genotypes are linked to obsessive-compulsive disorder. American Journal of Human Genetics 78, 815-826.

Karege F, Perret G, Bondolfi G, Schwald M, Bertschy G, Aubry JM (2002). Decreased serum brain-derived neurotrophic factor levels in major depressed patients. Psychiatry Research 109, 143-148.

Kaufman J, Yang BZ, Douglas-Palumberi H, Grasso D, Lipschitz D, Houshyar S, Krystal JH, Gelernter J (2006). Brain-derived neurotrophic factor-5-HTTLPR gene interactions and environmental modifiers of depression in children. Biological Psychiatry 59, 673-680.

Kendler KS, Kessler RC, Neale MC, Heath AC, Eaves LJ (1993). The prediction of major depression in women: toward an integrated etiologic model. American Journal of Psychiatry 150, 1139-1148.

Kendler KS, Kuhn JW, Prescott CA (2004). Childhood sexual abuse, stressful life events and risk for major depression in women. Psychological Medicine 34, 1475-1482.

Kendler KS, Kuhn JW, Vittum J, Prescott CA, Riley B (2005). The interaction of stressful life events and a serotonin transporter polymorphism in the prediction of episodes of major depression: a replication. Archives of General Psychiatry 62, 529-535.

Kessler RC, Magee WJ (1993). Childhood adversities and adult depression: basic patterns of association in a US national survey. Psychological Medicine 23, 679-690.

Kim JM, Stewart R, Kim SW, Yang SJ, Shin IS, Kim YH, Yoon JS (2007). Interactions between life stressors and susceptibility genes (5-HTTLPR and BDNF) on depression in Korean elders. Biological Psychiatry 62, 423-428.

Lenroot RK, Giedd JN (2006). Brain development in children and adolescents: insights from anatomical magnetic resonance imaging. Neuroscience and Biobehavioral Reviews 30, 718-729.

Lesch KP, Bengel D, Heils A, Sabol SZ, Greenberg BD, Petri S, Benjamin J, Muller CR, Hamer DH, Murphy DL (1996). Association of anxiety-related traits with a polymorphism in the serotonin transporter gene regulatory region. Science 274, 1527-1531.

Levinson DF (2006). The genetics of depression: a review. Biological Psychiatry 60, 84-92. 
Martinowich K, Lu B (2008). Interaction between BDNF and serotonin: role in mood disorders. Neuropsychopharmacology 33, 73-83.

Mattson MP, Maudsley S, Martin B (2004). BDNF and 5-HT: a dynamic duo in age-related neuronal plasticity and neurodegenerative disorders. Trends in Neurosciences 27, 589-594.

May-Chahal C, Cawson P (2005). Measuring child maltreatment in the United Kingdom: a study of the prevalence of child abuse and neglect. Child Abuse and Neglect 29, 969-984.

McCutcheon VV, Heath AC, Nelson EC, Bucholz KK, Madden PA, Martin NG (2008). Accumulation of trauma over time and risk for depression in a twin sample. Psychological Medicine. Published online: 4 June 2008. doi:10.1017/S0033291708003759.

Nemeroff CB (2004). Neurobiological consequences of childhood trauma. Journal of Clinical Psychiatry 65 (Suppl. 1), 18-28.

Nestler EJ, Barrot M, Dileone RJ, Eisch AJ, Gold SJ, Monteggia LM (2002). Neurobiology of depression. Neuron 34, 13-25.

Owens MJ, Nemeroff CB (1998). The serotonin transporter and depression. Depression and Anxiety 8 (Suppl. 1), 5-12.

Pak CS (2006). Types of gene-environment interplay and their statistical properties. In Beyond Nature and Nurture in Psychiatry: Genes, Environment and their Interplay (ed. J. MacCabe, O. O'Daly, M. R. Murray, P. McGuffin and P. Wright), pp. 11-17. Informa Healthcare: London.

Perroud N, Courtet P, Vincze I, Jaussent I, Jollant F, Bellivier F, Leboyer M, Baud P, Buresi C, Malafosse A (2008). Interaction between BDNF Val66Met and childhood trauma on adult's violent suicide attempt. Genes, Brain and Behaviour 7, 314-322.

Roy A, Hu XZ, Janal MN, Goldman D (2007). Interaction between childhood trauma and serotonin transporter gene variation in suicide. Neuropsychopharmacology 32, 2046-2052.

StataCorp (2005). STATA Statistical Software: Release 9.1. Stata Corporation, College Station, TX.

Stein MB, Schork NJ, Gelernter J (2008).

Gene-by-environment (serotonin transporter and childhood maltreatment) interaction for anxiety sensitivity, an intermediate phenotype for anxiety disorders. Neuropsychopharmacology 33, 312-319.

Teicher MH, Andersen SL, Polcari A, Anderson CM, Navalta CP (2002). Developmental neurobiology of childhood stress and trauma. Psychiatric Clinics of North America 25, 397-426, vii-viii.

UCLA: Academic Technology Services (2008). How can I understand a categorical by continuous interaction? (www.ats.ucla.edu/stat/stata/faq/catcon.htm). Accessed 1 June 2008.

Uher R, McGuffin P (2008). The moderation by the serotonin transporter gene of environmental adversity in the aetiology of mental illness: review and methodological analysis. Molecular Psychiatry 13, 131-146.

Wichers M, Kenis G, Jacobs N, Mengelers R, Derom C, Vlietinck R, Van Os J (2008). The BDNF

Val ${ }^{66}$ Met $\times 5$-HTTLR $\times$ child adversity interaction and depressive symptoms: an attempt at replication. American Journal of Medical Genetics. Part B: Neuropsychiatric Genetics 141, 120-123. 